\title{
Proinflammatory cytokine polarization in type 2 diabetes
}

\author{
MERVAT M. BAHGAT, DALIA R. IBRAHIM
}

Nuclear Research Center, Atomic Energy Authority, Cairo, Egypt

\begin{abstract}
Subclinical inflammatory reaction is associated with non-insulin dependent diabetes. Therefore, the aim of the present study is to describe the effect of the three cytokines: interferon $\gamma($ IFN- $\gamma)$, interleukin (IL)-4 and IL-5 on the development of type 2 diabetes (T2D). Forty-five volunteers (after their permission) were participated in this work; according to their clinical examination and laboratory investigations (fasting blood sugar, 2 hours postprandial, HbAlc and lipid profile), they were divided into thirteen control (non-diabetic) (five females and eight males) and thirty-two diabetic patients (twenty-one females and eleven males). Thereafter, their sera were evaluated for $C$-reactive protein (CRP), $I F N-\gamma, I L-4$ and $I L-5$. The results revealed an increasing trend of CRP and a significant increase of $I F N-\gamma$ in diabetic patients with no sex difference. A positive correlation between IFN- $\gamma$ and both IL-4 and IL-5 in control, and a positive correlation between $I L-4$ and IL-5 in diabetic patients had been visualized. These results denoted that there may be an association of the pro-inflammatory cytokines in the etiology of diabetes mellitus type 2.
\end{abstract}

Key words: cytokines, proinflammatory, type 2 diabetes, interleukin 4, interferon $\gamma$, interleukin 5.

(Cent Eur J Immunol 2020; 45 (2): 170-175)

\section{Introduction}

Several evidences revealed that type 2 diabetes (T2D) is a state of low-grade inflammation and reducing inflammation is an important outcome for T2D treatment since it caused balance between the pro-inflammatory and anti-inflammatory cytokines. Removal of tumor necrosis factor $\alpha(\mathrm{TNF}-\alpha)$ which is an inflammatory mediator protects against insulin resistance and salicylates intake improves insulin sensitivity [1-5]. As mentioned earlier, inflammation plays a major role in the development of T2D [6, 7]. However, there are other factors like genetic determinants, nutritional factors, and life style [8], that may contribute in the pathogenesis of non-insulin dependent diabetes.

Specific T cell subsets imbalance are responsible for many inflammatory and autoimmune disorders $[9,10]$. Th1/Th2 cytokines imbalance has been reported in chronic disease progression [11-14] and in metabolic syndrome [15]. The Th1 pro-inflammatory cytokines such as interferon $\gamma($ IFN- $\gamma$ ) and interleukin (IL)-2 activate macrophages and are involved in inflammatory immune responses. IFN- $\gamma$ had been identified by Rocha et al. [16] to have a role in diet-induced adipose inflammation, obesity, and glucose intolerance in vivo. McGillicuddy et al. [17] suggested that IFN- $\gamma$ caused a time-dependent reduction of insulin-stimulated glucose uptake which is indicative of insulin resistance.
Activated Th2 cells secrete cytokines such as IL-4, IL-5, IL-10 and IL-13, which have anti-inflammatory properties and are involved in antibody production, eosinophil activation, and suppression of macrophage functions $[12,13,18]$. IL-4 which is secreted also by basophils and mast cells has pleiotropic functions including Th2 differentiation, B-cell proliferation and immunoglobulin class switching [19]. IL-5 is another important Th2 cell-derived cytokine. It regulates the expression of diverse genes; these genes are partly responsible in proliferation, cell survival, maturation and effector functioning of B cells and eosinophils [20].

Therefore, the aim of the present study is to evaluate the levels of cytokines termed IFN- $\gamma$, IL-4 and IL-5 in Egyptian males and females suffering from T2D in an attempt to study the imbalance between the pro-inflammatory and anti-inflammatory immune response in diabetic patients.

\section{Material and methods}

\section{Patients}

Thirty-two patients (21 females and 11 males) with T2D and 13 non-diabetic controls (five females and eight males) were participated in the present study. All patients with T2D were receiving appropriate diet and oral hypo-

Correspondence: Dalia R. Ibrahim, PhD, Nuclear Research Center, Atomic Energy Authority, Egypt, 9, Sarai St., Apt. 904, Manial, 11553 Cairo, Egypt, e-mail: dr.dalia_ramzy@yahoo.com Submitted: 24.03.2017; Accepted: 16.08.2017 
glycemic agents as glucose-lowering medication at the time of experiment. The age of the diabetic subjects ranged from 30 to 65 years while the age of the healthy control subjects lied between 32 and 60 years. Family history, duration of diabetes, current medication and past history of infectious diseases or heart attack were thoroughly collected from every subject. With the exception of oral hypoglycemic agents, no other medications were taken. Clinical examination was recorded including, height, weight, body mass index (BMI - weight/height ${ }^{2}$ ), blood pressure, heart and chest examination. Patients with acute or chronic infection, hepatic or renal disease, malignancy, rheumatologic disorder and any clinical cardiovascular disease were excluded. The BMI of all subjects were between 19 and $24.9 \mathrm{~kg} / \mathrm{m}^{2}$.

\section{Biochemical analysis}

After clinical examination, 12 hours fasting blood samples were taken, introduced into two tubes, one tube with EDTA for analysis of glycated hemoglobin (HbA1c) and from the other tube serum was separated for determination of CRP, fasting blood sugar (FBS) and lipid profile (cholesterol, triglyceride, HDL, LDL). Another specimen was taken from the volunteers after 2 hours for the evaluation of 2 hours postprandial blood sugar (2h PP). FBS, $2 \mathrm{~h}$ PP and $\mathrm{HbA} 1 \mathrm{c}$ were measured to evaluate the diabetic condition of the individuals; CRP was evaluated to check the pro-inflammatory condition of patients and the lipid profile was analyzed to assess changes accompanying T2D.

\section{Cytokines measurements}

After the evaluation of these confirmatory results, five milliliters of whole-blood samples were collected from both patients and controls, using a standard venipuncture technique. Serum samples were obtained after centrifugation at $800 \times \mathrm{g}$ for $10 \mathrm{~min}$ and stored at $-80^{\circ} \mathrm{C}$ until assayed.

The concentration of the pro-inflammatory cytokine, IFN- $\gamma$, was evaluated by radio-immunoassay (RIA). IL-4 and IL-5 which are anti-inflammatory cytokines, were both determined in the sera by ELISA kits (enzyme-linked immunosorbent assay) according to the manufacturer's instructions.

\section{Measurement of serum IFN- $\gamma$}

The concentration of IFN- $\gamma$ was evaluated by radio-immunoassay using Bio-source Europe S.A. (Belgium) kit. IFN- $\gamma$ IRMA is an immunoradiometric assay based on coated-tube separation and on the oligoclonal system R, in which several monoclonal antibodies directed against distinct epitope of IFN- $\gamma$ have been used. The capture antibodies are attached to the lower and inner surface of the plastic tube. Standards or samples, added to the tubes will at first show low affinity for antibodies. The signal anti- body labeled with I-125, will trigger the immunological reaction. After washing, the remaining radioactivity bound to the tube reflects the antigen concentration.

\section{Measurement of serum IL-4}

IL-4 was determined by ELISA using RayBiotech (Inc. 3607 Parkway Lane, Suite 100, Narcross GA 30092) kit. This assay employs an antibody specific for human IL-4 coated on a 96-well plate. Standards and samples are pipetted into the wells and IL-4 present in a sample is bound to the wells by the immobilized antibody. The wells are washed and biotinylated anti-human IL-4 antibody is added. After washing away unbound biotinylated antibody, HRP-conjugated streptavidin is pipetted to the wells. The wells are again washed, a TMB substrate solution is added to the wells and color develops in proportion to the amount of IL-4 bound. The Stop Solution changes the color from blue to yellow, and the intensity of the color is measured at $450 \mathrm{~nm}$.

\section{Measurement of serum IL-5}

IL-5 was estimated using Boster biological technology LTD (USA) kit. Boster's human IL-5 ELISA Kit is based on standard sandwich enzyme-linked immune-sorbent assay technology. Human IL-5 specific-specific monoclonal antibodies are precoated onto 96-well plates. The human specific detection monoclonal antibodies are biotinylated. The test samples and biotinylated detection antibodies are added to the wells subsequently and then followed by washing with PBS or TBS buffer. Avidin-Biotin-Peroxidase Complex is added and unbound conjugates are washed away with PBS or TBS buffer. HRP substrate TMB is used to visualize HRP enzymatic reaction. TMB is catalyzed by HRP to produce a blue color product that changes into yellow after adding acidic stop solution. The density of yellow is proportional to the human IL-5 amount of sample captured in plate.

\section{Statistical analysis}

Results were presented as means \pm standard error (SE). Paired Student test ( $t$-test) was used to analyze sample averages. The correlation between the variables were analyzed by Pearson's correlation test [21]. The normality of distribution were evaluated by Kolmogorov-Smirnov test. No significant changes were observed between males and females; therefore, we added all the individuals, males and females, in one group.

\section{Results}

\section{Type 2 diabetes raises the levels of all biochemical tests}

All the tested parameters (FBS, 2h PP, cholesterol, triglyceride, HDL, LDL, HBA1c and CRP) showed increase in 
Table 1. Statistical analysis of FBS, $2 \mathrm{~h}$ PP, HBA1c, CRP, cholesterol, triglycerides, HDL and LDL values in controls and diabetic patients

\begin{tabular}{|c|c|c|c|}
\hline Parameters & Control & T2D & Normal range \\
\hline FBS (mg/dl) & $87 \pm 2.17$ & $114 \pm 3.01$ & $80-120$ \\
\hline $2 \mathrm{~h}$ PP (mg/dl) & $89 \pm 10.11$ & $169 \pm 3.12$ & $80-120$ \\
\hline $\mathrm{HbA1c}(\%)$ & $5.5 \pm 0.87$ & $8.55 \pm 1.01$ & Up to 6 \\
\hline $\mathrm{CRP}(\mathrm{mg} / \mathrm{l})$ & $6.08 \pm 0.68$ & $10.33 \pm 1.34$ & $0-10$ \\
\hline Cholesterol (mg/dl) & $189 \pm 4.52$ & $257 \pm 5.72$ & Up to 200 \\
\hline Triglycerides(mg/dl) & $83 \pm 7.33$ & $137 \pm 2.93$ & Up to 150 \\
\hline $\mathrm{HDL}(\mathrm{mg} / \mathrm{dl})$ & $42 \pm 1.07$ & $44 \pm 1.75$ & $35-55$ \\
\hline $\operatorname{LDL}(\mathrm{mg} / \mathrm{dl})$ & $107 \pm 2.33$ & $144 \pm 3.17$ & Up to 170 \\
\hline
\end{tabular}

Table 2. Statistical analysis of IFN- $\gamma$, IL-4 and IL-5 values in controls and diabetic patients

\begin{tabular}{lcccc}
\hline Parameters & $\begin{array}{c}\text { Control } \\
(\boldsymbol{n}=\mathbf{1 3})\end{array}$ & $\begin{array}{c}\text { T2D } \\
(\boldsymbol{n}=\mathbf{3 2})\end{array}$ & $\begin{array}{c}\text { Percent } \\
\text { of change }\end{array}$ & $\boldsymbol{p}$ value \\
\hline $\mathrm{IFN}-\gamma(\mathrm{IU} / \mathrm{ml})$ & $1.86 \pm 0.53$ & $9.64 \pm 3.68^{*}$ & 418 & $<0.05$ \\
\hline $\mathrm{IL}-4(\mathrm{pg} / \mathrm{ml})$ & $0.04 \pm 0.03$ & $0.13 \pm 0.05$ & 225 & $>0.05$ \\
\hline $\mathrm{IL}-5(\mathrm{pg} / \mathrm{ml})$ & $12.82 \pm 5.5$ & $15.64 \pm 4.99$ & 22 & $>0.05$ \\
\hline
\end{tabular}

The data are presented as mean $\pm S E$ and percentage of change. Significant at $p<0.05^{*}$. IFN- $\gamma$-interferon $\gamma, I L-4$ - interleukin 4, IL-5 - interleukin 5

Table 3. Correlation coefficient of IFN- $\gamma$, IL-4 and IL-5 in controls

\begin{tabular}{lccc}
\hline $\begin{array}{l}\text { Correlated } \\
\text { parameters }\end{array}$ & $\boldsymbol{r}$ value & $\boldsymbol{p}$ value & $\begin{array}{c}\mathbf{9 5 \%} \text { CI } \\
\text { (lower limit }- \text { upper limit) }\end{array}$ \\
\hline IFN- $\gamma \times \mathrm{IL}-4$ & $0.586^{*}$ & $<0.05$ & $(0.04-1.3)$ \\
\hline IFN- $\gamma \times \mathrm{IL}-5$ & $0.841^{* *}$ & $<0.01$ & $(0.6-1.85)$ \\
\hline IL-4 $\times$ IL-5 & 0.25 & $>0.05$ & $(-0.37-0.88)$ \\
\hline
\end{tabular}

Values of correlation coefficient are significant at $p<0.05^{*}$ and $p<0.01^{* *}$. IFN- $\gamma$ - interferon $\gamma, I L-4$ - interleukin $4, I L-5$ - interleukin 5

Table 4. Correlation coefficient of IFN- $\gamma$, IL-4 and IL-5 in diabetic patients

\begin{tabular}{lcc}
\hline Correlated parameters & $\boldsymbol{r}$ value & $\boldsymbol{p}$ value \\
\hline $\mathrm{IFN}-\gamma \times \mathrm{IL}-4$ & 0.107 & $>0.05$ \\
\hline $\mathrm{IFN}-\gamma \times \mathrm{IL}-5$ & 0.283 & $>0.05$ \\
\hline $\mathrm{IL}-4 \times \mathrm{IL}-5$ & $0.499^{*}$ & $<0.05$ \\
\hline $\begin{array}{l}\text { Values of correlation coefficient are significant at } p<0.05^{*} . \text { IFN- } \gamma-\text { interferon } \\
\gamma, \text { IL-4 }- \text { interleukin } 4, \text { IL-5 }- \text { interleukin-5 }\end{array}$
\end{tabular}

the diabetic persons compared to controls; they also showed an increase as regards to the normal range (Table 1).

\section{Rise in IFN- $\gamma$ level in diabetic patients}

The IFN- $\gamma$ is the only cytokine which showed significant $(p<0.05)$ increase in diabetic patients where the percentage of change mounted to $418 \%$. There was an insignificant increase in both IL-4 and IL-5 in the diabetic group compared to the control group, with a percentage of change $225 \%$ and $22 \%$ respectively (Table 2 ).

\section{Correlation between IFN- $\gamma$ and both IL-4 and IL-5 in the control group}

There was a positive significant correlation in the control group between IFN- $\gamma$ and both IL- 4 and IL-5 at $p<0.05$ and $p<0.01$ respectively and a positive insignificant correlation between IL-4 and IL-5 (Table 3).

\section{Correlation between IL-4 and IL-5 in the diabetic patients}

In diabetic patients, there was a positive significant ( $p$ $<0.05$ ) correlation between IL-4 and IL-5 and a positive insignificant correlation between IFN- $\gamma$ and both IL-4 and IL-5 (Table 4).

No correlations were observed between the tested cytokines and the duration of diabetes or BMI.

\section{Discussion}

In the present study HbA1c and CRP were chosen as an indicator of hyperglycemia in the past 3 months [22] and as a sensitive physiological marker of subclinical systemic inflammation [23] respectively. There is a correlation between cytokines production and CRP. Schultz and Arnold [24] and Sabanayagam et al. [25] stated that cytokines such as IL-6, IL-1 and TNF- $\alpha$ stimulate hepatic synthesis of CRP. Similarly Pepys and Hirschfield [26] concluded that the acute phase CRP was produced as part of pathophysiological conditions including infection and inflammation. The link that exist between diabetes and systemic inflammation is reflected in the circulatory levels of CRP in the present study and confirmed the finding of many studies [27-30].

T2D besides its classification as a metabolic disease, it is considered also as a subclinical inflammatory one with changes in immune cell function. In diabetes, the metabolic and immune pathways are interdependent; metabolic disorder in T2D and the associated inflammatory process seems to play an important role in the development of diabetes and its late complications [31].

The relation between inflammation and insulin resistance, the key primary defect underlying the development of T2D, originates through different mechanisms. Impair- 
ment of muscle cell insulin action can be caused by overproduction of nitric oxide resulting from the inflammatory cytokine stimulation, leading to induction of inducible nitric oxide synthase (iNOS) [32, 33]. The inflammatory signaling pathways can also become activated by metabolic stresses originating intracellular and extracellular from signaling molecules $[34,35]$. Additionally, the rise in mitochondrial production of reactive oxygen species (ROS) enhanced activation of inflammatory pathways [36, 37].

In the present study the high significant increase of the proinflammatory IFN- $\gamma$ might cause insulin resistance as suggested by McGillicuddy et al. [17]. They examined the effect of IFN- $\gamma$ on insulin sensitivity, lipid storage, and differentiation in human adipocytes. They found that IFN- $\gamma$ induced a time dependent reduction of insulin-stimulated glucose uptake and Akt (protein kinase B) phosphorylation, both indicative of insulin resistance.

IFN- $\gamma$ as a cytokine can be produced by NK, macrophages and helper T cells. Macrophages, as examined by Mosser and Edwards [38], have remarkable plasticity that allows them to change their phenotype and their physiology according to environmental signals, including alterations in the expression of surface proteins, the production of cytokines and pro-inflammatory mediators. It has been established that macrophages contributes to the proinflammatory milieu of the diabetic islet [39]. Several authors suggested that monocytes from T2D patients constitutively and inducibly secrete elevated levels of IL-6, IL-8, TNF- $\alpha$ and IL- 1 beta [38, 40-43] and decreased levels of the anti-inflammatory cytokine IL-10 [44]. However, it was demonstrated that monocytes and macrophages might have different origin with different lineage, though there might be some plasticity [45].

The present study agreed with the work of Jagannathan-Bogdan et al. [46], which showed that blood from T2D patients had increased circulating Th17 cells (proinflammatory subsets of T cells) and that T cells from T2D patients had increased production of IFN- $\gamma$, but produced healthy levels of IL-4. In contrast, they found that T2D patients had decreased percentage of CD4 ${ }^{+}$Tregs (anti-inflammatory subsets of $\mathrm{T}$ cells). In addition, it was stated that T2D patients also had elevated levels of serum IL-12 $[47,48]$, a cytokine that promotes Th1 differentiation and elevated IFN- $\gamma$ production [49-51].

The present work disagreed with that of Ahmad et al. [52] who showed in their study that plasma IL-5 levels were significantly lower in diabetic individuals as compared with non-diabetic counterparts. It seems that there is another factor which interferes with this cytokine, as the same authors observed in their study that IL-5 levels were significantly higher in obese diabetic population than overweight/ lean diabetic individuals. Madhumitha et al. also showed the suppression of Th2 serum cytokines in subjects with diabetic coronary artery disease [15]. The difference in results from ours may be caused due to different laboratory methods of cytokines analysis.

There was a positive correlation between IFN- $\gamma$ and both IL-4 and IL-5 in control subjects (Table 3) contrary to that observed in diabetic group. This condition in the control may reflect the importance of the balance between pro-inflammatory and anti-inflammatory subsets of $\mathrm{T}$ cells which is critical to maintain homeostasis and avoid inflammatory diseases. Since T2D had been identified in recent findings as an example of a chronic inflammatory disease, it is expected that DM promote pro-inflammatory cytokines production. The loss of correlation between IFN- $\gamma$, IL-4 and IL-5 in T2D patients most probably means that there is loss of homeostasis in T cell subsets balance and the $\mathrm{T}$ cells in T2D patients are skewed toward pro-inflammatory subsets that promote chronic inflammation in T2D.

The non-significant changes of IL-4 in diabetes may point to the nature of DM as a subclinical inflammatory disease, allowing no obvious release of this anti-inflammatory cytokine and supporting the finding of Jagannathan-Bogdan et al. [46] who stated that there was healthy levels of IL-4 in T2D patients. The significant positive correlation between IL-4 and IL-5 in diabetic patients (Table 4) pointed to the close association between the two cytokines.

The increase of IFN- $\gamma$, in addition to the positive correlation between IL-4 and IL-5 in diabetic patients may point to the association between inflammation and T2D In particular, the increase of proinflammatory cytokine IFN- $\gamma$ in diabetic individuals denoted this close association.

\section{Acknowledgements}

No funding was received for the study. The authors would like to thank Dr. Eman Mokhtar (PhD) for her assistance in the ELISA work in Abu Al Azayem laboratory and research unit. Many thanks for Dr. Hesham Abu El Nasr (General practitioner) for the clinical examination of the patients.

The authors declare no conflict of interest.

\section{References}

1. Hotamisligil GS, Shargill NS, Spiegelman BM (1993): Adipose expression of tumor necrosis factor-alpha: direct role in obesity-linked insulin resistance. Science 259: 87-91.

2. Uysal KT, Wiesbrock SM, Marino MW, Hotamisliqil GS (1997): Protection from obesity-induced insulin resistance in mice lacking TNF-alpha function. Nature 389: 610-614.

3. Hirosumi J, Tuncman G, Chang L, et al. (2002): A central role for JNK in obesity and insulin resistance. Nature 420: 333-336.

4. Yuan M, Konstantopoulos N, Lee J, et al. (2001): Reversal of obesity- and diet-induced insulin resistance with salicylates or targeted disruption of Ikkbeta. Science 293: 1673-1677. 
5. Hundal RS, Petersen KF, Mayerson AB, et al. (2002): Mechanism by which high-dose aspirin improves glucose metabolism in type 2 diabetes. J Clin Invest 109: 1321-1326.

6. Hotamisligil GS (2006): Inflammation and metabolic disorders. Nature 444: 860-867.

7. Wellen KE, Hotamisligil GS (2005): Inflammation, stress, and diabetes. J Clin Invest 115: 1111-1119.

8. Rosen ED, Spiegelman BM (2006): Adipocytes as regulators of energy balance and glucose homeostasis. Nature 444: 847853.

9. Sutton C, Brereton C, Keogh B, et al. (2006): A crucial role for interleukin (IL)-1 in the induction of IL-17-producing T cells that mediate autoimmune encephalomyelitis. J Exp Med 203: 1685-1691.

10. Furuzawa-Carballeda J, Vargas-Rojas MI, Cabral AR (2007): Autoimmune inflammation from the Th17 perspective. Autoimmun Rev 6: 169-175.

11. Murphy KM, Reiner SL (2002): The lineage decisions of helper T cells. Nat Rev Immunol 2: 933-944.

12. Jankovic D, Liu Z, Gause WC (2001): Th1- and Th2-cell commitment during infectious disease: asymmetry in divergent pathways. Trends Immunol 22: 450-457.

13. Lappin DF, MacLeod CP, Kerr A, et al. (2001): Anti-inflammatory cytokine IL-10 and T cell cytokine profile in periodontitis granulation tissue. Clin Exp Immunol 123: 294-300.

14. Gemmell E, Yamazaki K, Seymour GJ (2007): The role of $\mathrm{T}$ cells in periodontal disease: homeostasis and autoimmunity. Periodontol 2000 43: 14-40.

15. Madhumitha H, Mohan V, Deepa M, et al. (2014): Increased Th1 and suppressed Th2 serum cytokine levels in subjects with diabetic coronary artery disease. Cardiovasc Diabetol 13: 1.

16. Rocha VZ, Folco EJ, Sukhova G, et al. (2008): Interferon-gamma, a Th1 cytokine, regulates fat inflammation: a role for adaptive immunity in obesity. Circ Res 103: 467-476.

17. McGillicuddy FC, Chiquoine EH, Hinkle CC, et al. (2009): Interferon gamma attenuates insulin signaling, lipid storage, and differentiation in human adipocytes via activation of the JAK/STAT pathway. J Biol Chem 284: 31936-31944.

18. Kawashima N, Stashenko P (1999): Expression of bone-resorptive and regulatory cytokines in murine periapical inflammation. Arch Oral Biol 44: 55-66.

19. Nelms K, Keegan AD, Zamorano J, et al. (1999): The IL-4 receptor: signaling mechanisms and biologic functions. Annu Rev Immunol 17: 701-738.

20. Kouro T, Takatsu K (2009): IL-5- and eosinophil-mediated inflammation: from discovery to therapy. Int Immunol 21 : 1303-1309.

21. Lind DA, Masson DR (1996): Statistical techniques in business and economics ( $9^{\text {th }}$ ed.). McGraw-Hill, USA: 433-443.

22. Zoungas S, Chalmers J, Ninomiya T, et al. (2012): Association of $\mathrm{HbA1c}$ levels with vascular complications and death in patients with type 2 diabetes: evidence of glycaemic thresholds. Diabetologia 55: 636-643.

23. Su SC, Pei D, Hsieh CH, et al. (2011): Circulating pro-inflammatory cytokines and adiponectin in young men with type 2 diabetes. Acta Diabetol 48: 113-119.

24. Schultz D, Arnold PI (1990): Properties of four acute phase proteins: C-reactive protein, serum amyloid A protein, alpha 1-acid glycoprotein, and fibrinogen. Semin Arthritis Rheum 20: $129-147$.
25. Sabanayagam C, Shankar A, Lim SC, et al. (2011): Serum $\mathrm{C}$-reactive protein level and prediabetes in two Asian populations. Diabetologia 54: 767-775.

26. Pepys MB, Hirschfield GM (2003): C-reactive protein: a critical update. J Clin Invest 111: 1805-1812.

27. de Rekeneire N, Peila R, Ding J, et al. (2006): Diabetes, hyperglycemia, and inflammation in older individuals: the health, aging and body composition study. Diabetes Care 29: 1902-1908.

28. Belfki H, Ben Ali S, Bougatef S, et al. (2012): Association between C-reactive protein and type 2 diabetes in a Tunisian population. Inflammation 35: 684-689.

29. Ehiaghe AF, Agbonlahor DE, Tatfeng YM, et al. (2013): Serum $C$ reactive protein level in type 2 diabetes mellitus patients attending diabetic clinic in Benin City, Nigeria. J Diabetes Mellitus 3: 168-171.

30. Misra DP, Das S, Sahu PK (2012): Prevalence of inflammatory markers (high-sensitivity C-reactive protein, nuclear factor-kappa B, and adiponectin) in Indian patients with type 2 diabetes mellitus with and without macrovascular complications. Metab Syndr Relat Disord 10: 209-213.

31. Philip S, Abraham P, Kanakasabai G, et al. (2012): Serum high sensitive $\mathrm{C}$-reactive protein and anticardiolipin antibody level in CAD patients with and without type 2 diabetes mellitus. Int J Appl Biol Pharm 3: 196-202.

32. Shimabukuro M, Ohneda M, Lee Y, Unger RH (1997): Role of nitric oxide in obesity-induced beta cell disease. J Clin Invest 100: 290-295.

33. Perreault M, Marette A (2001): Targeted disruption of inducible nitric oxide synthase protects against obesity-linked insulin resistance in muscle. Nat Med 7: 1138-1143.

34. Ozcan U, Cao Q, Yilmaz E, et al. (2004): Endoplasmic reticulum stress links obesity, insulin action, and type 2 diabetes. Science 306: 457-461.

35. Nakatani Y, Kaneto H, Kawamori D, et al. (2005): Involvement of endoplasmic reticulum stress in insulin resistance and diabetes. J Biol Chem 280: 847-851.

36. Lin Y, Berg AH, Iyengar P, et al. (2005): The hyperglycemia-induced inflammatory response in adipocytes: the role of reactive oxygen species. J Biol Chem 280: 4617-4626.

37. Furukawa S, Fujita T, Shimabukuro M, et al. (2004): Increased oxidative stress in obesity and its impact on metabolic syndrome. J Clin Invest 114: 1752-1761.

38. Mosser DM, Edwards JP (2008): Exploring the full spectrum of macrophage activation. Nat Rev Immunol 8: 958-969.

39. Morris DL (2015): Minireview: Emerging concepts in islet macrophage biology in type 2 diabetes. Mol. Endocrinol 29: 946-962.

40. Pickup JC (2004): Inflammation and activated innate immunity in the pathogenesis of type 2 diabetes. Diabetes Care 27: 813-823.

41. Pickup JC, Crook MA (1998): Is type II diabetes mellitus a disease of the innate immune system? Diabetologia 41: 1241-1248.

42. Giulietti A, van Etten E, Overbergh L, et al. (2007): Monocytes from type 2 diabetic patients have a pro-inflammatory profile. 1,25-Dihydroxyvitamin $\mathrm{D}(3)$ works as antiinflammatory. Diabetes Res Clin Pract 77: 47-57.

43. Hatanaka E, Monteagudo PT, Marrocos MS, Campa A (2006): Neutrophils and monocytes as potentially important sources of proinflammatory cytokines in diabetes. Clin Exp Immunol 146: 443-447. 
44. Jagannathan M, McDonnell M, Liang Y, et al. (2010): Tolllike receptors regulate $\mathrm{B}$ cell cytokine production in patients with diabetes. Diabetologia 53: 1461-1471.

45. Guilliams M, Ginhoux F, Jakubzick C, et al. (2014): Dendritic cells, monocytes and macrophages: a unified nomenclature based on ontogeny. Nat Rev Immunol 14: 571-578.

46. Jagannathan-Bogdan M, McDonnell ME, Shin H, et al. (2011): Elevated proinflammatory cytokine production by a skewed $\mathrm{T}$ cell compartment requires monocytes and promotes inflammation in type 2 diabetes. J Immunol 186: 1162-1172.

47. Wegner M, Winiarska H, Bobkiewicz-Kozłowska T, Dworacka M (2008): IL-12 serum levels in patients with type 2 diabetes treated with sulphonylureas. Cytokine 42: 312-316.

48. Tsiavou A, Degiannis D, Hatziagelaki E, et al. (2004): Intracellular IFN-gamma production and IL-12 serum levels in latent autoimmune diabetes of adults (LADA) and in type 2 diabetes. J Interferon Cytokine Res 24: 381-387.

49. Manetti R, Parronchi P, Giudizi MG, et al. (1993): Natural killer cell stimulatory factor (interleukin 12 [IL-12]) induces Thelper type 1 (Th1)-specific immune responses and inhibits the development of IL-4-producing Th cells. J Exp Med 177: 1199-1204.

50. Wu CY, Demeure C, Kiniwa M, et al. (1993): IL-12 induces the production of IFN gamma by neonatal human CD4 T cells. J Immunol 151: 1938-1949.

51. Puddu P, Fantuzzi L, Borghi P, et al. (1997): IL-12 induces IFN-gamma expression and secretion in mouse peritoneal macrophages. J Immunol 159: 3490-3497.

52. Ahmad R, Al-Roub A, Koshy M, et al. (2015): Relationship of Il-5 with Th1 and Th2 cytokines in individuals with or without type-2 diabetes. J Glycomics Lipidomics 5: 134. 